\title{
An educational approach based on a non-injury model compared with individual symptom-based physical training in chronic LBP. A pragmatic, randomised trial with a one-year follow-up
}

Pia H Sorensen ${ }^{1}$, Tom Bendix ${ }^{1,2^{*}}$, Claus Manniche ${ }^{1}$, Lars Korsholm³ ${ }^{3}$ Dorte Lemvigh ${ }^{1}$, Aage Indahl ${ }^{4}$

\begin{abstract}
Background: In the treatment of chronic back pain, cognitive methods are attracting increased attention due to evidence of effectiveness similar to that of traditional therapies. The purpose of this study was to compare the effectiveness of performing a cognitive intervention based on a non-injury model with that of a symptom-based physical training method on the outcomes of low back pain (LBP), activity limitation, LBP attitudes (fear-avoidance beliefs and back beliefs), physical activity levels, sick leave, and quality of life, in chronic LBP patients.

Methods: The study was a pragmatic, single-blind, randomised, parallel-group trial. Patients with chronic/recurrent LBP were randomised to one of the following treatments: 1. Educational programme : the emphasis was on creating confidence that the back is strong, that loads normally do not cause any damage despite occasional temporary pain, that reducing the focus on the pain might facilitate more natural and less painful movements, and that it is beneficial to stay physically active. 2 . Individual symptom-based physical training programme : directionalpreference exercises for those centralising their pain with repetitive movements; 'stabilising exercises' for those deemed 'unstable' based on specific tests; or intensive dynamic exercises for the remaining patients. Follow-up questionnaires (examiner-blinded) were completed at 2,6 and 12 months. The main statistical test was an ANCOVA adjusted for baseline values.
\end{abstract}

Results: A total of 207 patients participated with the median age of 39 years (IQR 33-47); 52\% were female, 105 were randomised to the educational programme and 102 to the physical training programme. The two groups were comparable at baseline. For the primary outcome measures, there was a non-significant trend towards activity limitation being reduced mostly in the educational programme group, although of doubtful clinical relevance. Regarding secondary outcomes, improvement in fear-avoidance beliefs was also better in the educational programme group. All other variables were about equally influenced by the two treatments. The median number of treatment sessions was 3 for the educational programme group and 6 for the physical training programme group.

Conclusions: An educational approach to treatment for chronic LBP resulted in at least as good outcomes as a symptom-based physical training method, despite fewer treatment sessions.

Trial registration: Clinicaltrials.gov: \# NCT00410319

\footnotetext{
* Correspondence: tbendix@health.sdu.dk

${ }^{1}$ The Back Research Center, part of Clinical Locomotion Science, Funen

Hospital, Ringe, and the University of Southern Denmark, Denmark

Full list of author information is available at the end of the article
} 


\section{Background}

Increased attention is being directed towards cognitive behavioural issues in the management of chronic low back pain (cLBP). One reason is that cognitive interventions have generally demonstrated effectiveness in selfreported disability [1-5] and sick leave[5-12] similar to that of traditional treatments. Another reason is that benefits from traditional physical treatments of cLBP are generally only of moderate clinical efficacy[13].

A cognitive approach in this context is not a welldefined term. It covers a spectrum from an educational approach to cognitive behavioural treatments delivered by psychologists. For LBP, our impression is that most reported cognitive interventions can be classified as educational approaches designed to produce altered behaviour through insight and understanding, and not psychological treatments as such. A crucial part of such interventions will be what kind of insight emerges, how effectively it is delivered, and the person's internalisation of the message received.

Cognitive theories include elements of central pain perception as well as optimisation of peripheral muscular control[14-23].

Among several cognitive/educational models, the one by Indahl has been shown to be particularly effective regarding return-to-work $[6,8,9]$. This was so in the early 1990s, where the alternative was often a "be-careful-withyour-back!" attitude. His brief intervention (about 3 hours) was based on a 'non-injury model' intended to focus on the back as a strong structure, where pain was not to be taken as a sign of injury caused by any wrongdoing or 'inappropriate' behaviour, and that natural movements are more appropriate than movements influenced by uncertainty and a focus on carefulness [15]. The robustness of the spine seems well elucidated: It can withstand most kinds of 'abuse' even over years [24-28]. In some studies, loading even seems to protect the intervertebral discs,[29] indicating that discs respond to physical loading as do most other connective tissues [30,31].

In contrast, the 'injury model,' where pain is taken as a sign of injury from increased loading, seems not to have been useful as a basis for clinical management $[32,33]$. In common LBP it has not been possible so far to substantiate the nature of injury or spinal structure affected. This has left us with uncertainty as to how to manage much cLBP, reflected in the wide range of treatments recommended from bed rest to functional restoration. The injury model has unfortunately been useful in medicalising common LBP, but useless clinically to answer even simple questions from patients such as: What is wrong? Why do I hurt? When is the spine strong enough for activity? For other musculoskeletal injuries such as broken legs or sprained ankles, answers are available, but this is not the case for common LBP.

It is well known that certain jobs and working positions are associated with increased back pain [34,35]. However, it is not clear how far daily physical loading causes LBP or whether having an existing pain leads to greater problems in physically demanding jobs. Regardless of which is the cause and which is the effect, the injury model does not seem to be adequate in explaining degeneration or common painful conditions.

Regarding exercises and other physical therapies in cLBP, randomised controlled trials (RCT) generally show small effect sizes on a group basis. However, subgroup analyses suggest greater effectiveness for such treatments in people with particular clinical profiles. Individualised, symptom-based physical training programmes had, at the preparation of our study, shown success in an RCT with acute patients[36] and with sciatica patients[37]. Moreover, for those whose pain centralised with McKenzie assessment procedures, benefits were documented for directionally-preferred exercises [38]. Furthermore, the benefit of stabilising exercises had been demonstrated in one large[39] and two smaller studies[40,41]. Also for such exercises, it seemed that for particular subgroups deemed 'unstable', stabilising exercises were effective. Intensive exercises had previously also shown some efficacy[13].

The specific aims of this study were to compare the effects of prescribing for cLBP patients either:

- an educational approach designed to improve confidence in the robustness of the spine, or

- symptom-based physical training treatment

on the primary outcomes of back pain and activity limitation, and secondary outcomes of LBP attitudes (fear-avoidance/back beliefs), physical activity levels, work ability, quality of life, sick leave, and a number of other health-care treatments.

\section{Methods \\ Study Design}

The study was a pragmatic, single-blinded, randomised, parallel-group trial with follow-up periods of 2, 6 and 12 months. It was conducted in accordance with The Declaration of Helsinki 2000 and approved by the local Research Ethics Committee (ref. no. VF 20040016).

\section{Study Population}

CLBP patients were recruited from the clinic at a multidisciplinary non-surgical Back Center. The patients were referred to the clinic from general practitioners and chiropractors from across the Funen county in Denmark. Most had already had various treatments, with less than satisfactory outcomes. 
The following inclusion criteria were chosen: 18 to 60 years of age, LBP for at least 4 out of the previous 12 months and a mean LBP score over the last 14 days of $\geq 4$ (scale $0-10$ ). The back pain had to be greater than any associated leg pain. Exclusion criteria included the presence of cancer, traditional inflammatory diseases (Bechterew, Reiters disease, etc.), sequelae after earlier back surgery, conditions of competing joint or muscle disease, psychiatric illnesses, or any general disease that would hinder intensive physical training. Due to the use of MRI scanning in this study, current pregnancy or the presence of magnetic metal in the body were additional exclusion criteria.

The original power analysis was designed to identify a difference between return-to-work proportions from $80 \%$ to $60 \%$, and showed that $\mathrm{n}=100$ in each arm would give a power of $84 \%$. However due to a subsequent recognition that pain and pain-related activity might be earlier and more sensitive indicators of changed behaviour resulting in earlier return-to-work, these were raised to the status of primary variables.

\section{Procedure}

Recruitment and initial physical examinations were conducted in the period from June 2004 to October 2005. Consecutively referred patients, classified as suitable on the basis of screening criteria, were informed about the study. People were informed that the purpose of the study was to compare two different treatments for chronic/recurrent LBP: one with a primary concentration on fear-reducing information, and the other on symptom-based physical training. They were also informed that the current waiting period for assessment and treatment at the clinic was more than 3 months, whereas participation in the study would result in an MRI scan, with earlier diagnosis and treatment.

All the people who then expressed an interest in participating in the study underwent a comprehensive examination by the same clinician (PHS) lasting up to $1 \frac{1 / 2}{2}$ hours, during which further assessment against the inclusion and exclusion criteria was performed. A diagnosis was not given to the patient at this point, and the objective findings were explained to them in a neutral way. Patients not included received the usual treatment offered at The Back Center.

The patients who were considered eligible for inclusion were then asked to provide written informed consent and subsequently to visit a secretary who managed the randomisation, using unmarked sealed envelopes, containing a note on which was randomly written either:

- Educational programme (EDUC), or

- Physical training programme (TRAIN).

During this and following procedures, the principal investigator was not present.
After randomisation, the patients completed self-report questionnaires.

They received a schedule, including a date for an MRI scan in the following week, and an appointment for the first consultation with either a medical professor (TB) for EDUC, or with a specially trained physiotherapist for TRAIN.

\section{Blinding}

The same investigator (PHS) managed the baseline examination and controlled the follow-up forms, blinded to the treatment group. In the data, treatment groups were named $\mathrm{X}$ and $\mathrm{Y}$ until the end of analyses.

\section{MRI}

To avoid a possible variation across the participants in level of confidence resulting from some having had an MRI and others not, all had a standard lumbar MRI (0.2 T MRI-system, Siemens Open Viva). Two experienced claustrophobia and failed to undergo the scan. One patient had a pelvic MRI only, because her symptoms were located around the sacro-iliac joints. The imaging protocol consisted of one localiser and four imaging sequences. Most patients demonstrated degenerative changes. More detailed imaging results will be published separately.

\section{Interventions}

During the first visit, both groups received an additional specific physical examination. In the EDUC group this was short, and mostly directed towards possible tense and tender muscles and a fear-avoidance movement pattern. In the TRAIN group, possible directional preference and neuromuscular stability were tested (see below). In both groups, explanations of the MRI scan, of the objective findings from the baseline examination, and if possible, a clarification of the pathology causing the patient's symptoms, were given. Especially in the EDUC group disc degeneration was explained thoroughly, but in both groups it was emphasised that the relationship between disc degeneration and pain is weak.

\section{The educational programme}

The educational approach was adapted from Indahl[9] and is described below. The participants attended one to three 30-60 minute sessions, at one to three week intervals, the first and third of which were carried out by TB. The second was a one-hour group session with approximately five to seven participants, often accompanied by a relative, and led by a physiotherapist experienced in chronic pain management. They were also given a $\mathrm{CD}$ with a PowerPoint presentation for studying at home on general biological and cognitive aspects of back pain, as described below.

Initially, the patient's perception of his/her back problem was mapped, for example, its course, the way 
he/she handled it, the precautions he/she was taking, and the prognosis. The goal was to give the patient a new insight, if needed, aimed at changing his/her perception towards one that was less focussed on the current LBP condition and instilled more confidence in managing the condition into the future.

Information on pathoanatomy and physiology included the view of their own lumbar MRI scan, emphasising the positive aspects rather than focusing on possible abnormalities, unless they had particular significance. They were informed that pain episodes from high-load movements are temporary and do not cause permanent damage.

It was emphasised that pain has a physical cause, whether it could be found or not. Tension could increase pain by stressing tender joints and/or by primary muscular pain. Awkward movements could also occur if they were carried out with overly conscious control, in contrast to natural movements, especially when accompanied by fear of pain. Several simple metaphors were used to help reinforce this message. Such information may assist in the performance of more natural spinal movements and accordingly result in less pain. This mental attitude requires an understanding of the above mechanisms.

One specific back-muscle stretching (seated flexion + rotation) exercise was practised with the patients.

\section{Symptom-based physical training programme}

At the first consultation, the physiotherapist began with a complete Mechanical Diagnostic Therapy (MDT) examination to find a possible directional preference. In the case of centralisation (where radiating pain shortened its radiating distance) or just pain relief with this procedure, patients were treated with the relevant directional-preference exercises, along with advice on optimal postures. The emphasis was on gradual progression with an attempt to eventually regain full function.

If such MDT testing was negative (Fig. 1), the patient was tested for neuromuscular stability.

This included assessing the patient's usually painful movements when also performing so-called stabilisation procedures. If he/she could not activate the trunk muscles appropriately, or had pain relief by pretension of the trunk muscles during exercise, they were deemed 'unstable.' Accordingly, an individual programme was initiated with an emphasis on regaining stability. The exercise regime went from muscular stabilisation in basic neutral positions towards stabilisation in everyday functions.

If patients were not classified as having a directional preference or as being unstable, they were assigned to an intensive dynamic exercise programme. This programme emphasised adequate balance, endurance and strength exercises of the trunk muscles, fitness training and 'therapy-ball' exercises. This programme was

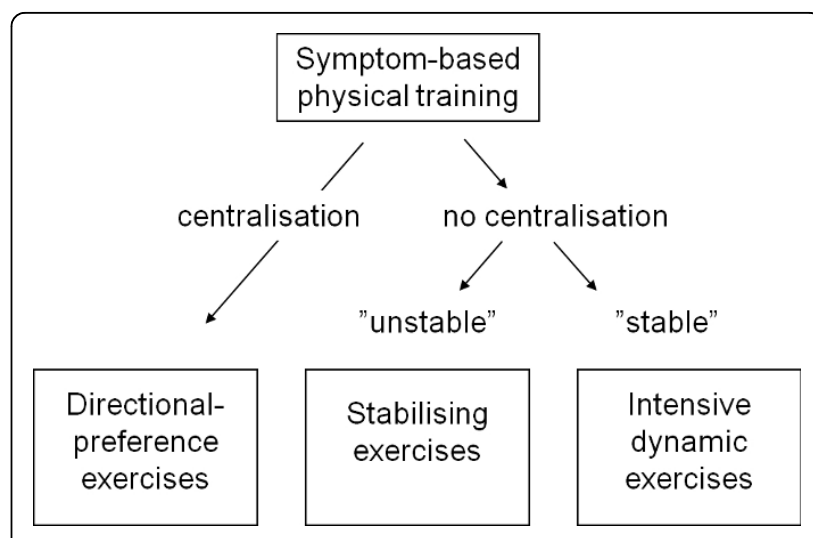

Figure 1 The symptom-based flow in determining the individual treatments

conducted in a group setting but was concluded with an assessment of each individual's final muscle control.

In addition, participants in the TRAIN group were treated in a 'best practice' manner that augmented their physical training with other therapies. This meant that several health professionals could be involved as deemed relevant by the physical therapist: a nurse (medication or pain management), a chiropractor (manipulative therapy), a doctor (steroid injection) or conferences (multidisciplinary approaches to pain management) in continued treatment plans. Each patient also received individual recommendations for further training at home, outside or in a club/training centre.

The physical training programmes were managed by two physiotherapists, one who was a credentialled MDT therapist, and the other who had attended all MDT courses but was not yet a graduate. They had completed training courses in kinetics control and had several years' experience with cLBP patients.

\section{Assessment and outcomes measures}

The patients completed questionnaires at baseline and at 2, 6 and 12 months after the end of the treatment. Because treatment duration differed, we deemed the treatment period to end 2 months after the first examination. In other words, the 2-month follow-up period covered 2-4 months after baseline.

Baseline and/or outcomes data were collected on the following clinical characteristics:

Demographic data : gender, age, marital status, education, occupation, sick leave, level of physical activity (sport, gardening etc).

\section{Primary outcomes \\ Pain intensity [42]}

Numerical Rating Scale 0 (no pain) -10 (as bad as could be), averaged over the preceding two weeks. 


\section{Activity limitation ('LBP Rating Scale')[42]}

a 15-item questionnaire covering activity limitation averaged over 2 weeks, each item scoring 0,1 or 2 (significant complaints); range $0-30$. These two outcome measures have had widespread use over the past two decades, especially in RCTs from Denmark.

\section{Roland Morris Disability Questionnaire (RMQ)[43]}

a 23-item tool, where each question is scored 0 (no disability) or 1 (some disability). The RMQ was undertaken only at baseline enabling a comparison with other studies.

\section{Secondary outcomes LBP attitudes}

Fear-Avoidance Beliefs Questionnaire (FABQ) [44]: assessed the patient's beliefs about work and physical activity as influenced by back trouble. Score 0 (lowest) to 6 (highest level of fear-avoidance belief). Of two subscales, a 4-item physical activity scale (score range 0-24) was used only. The work-related subscale was not used, since not all patients were employed. Fear avoidance was also assessed with Hasenbring's method, which will be reported separately.

Back Beliefs Questionnaire (BBQ)[45]: comprising 9 items reflecting beliefs about the consequences of LBP. Each item of the BBQ was scored 0 (lowest) to 6 (highest impact).

Physical activity : They were asked how many minutes weekly they had spent on several listed physical activities from intensive sport, to biking/walking, to gardening etc.

Work ability : an 11-item scale on the patient's work situation[46]. The answers were dichotomised afterwards into able to work or not. It is presented as 'percentage of the group capable of work'.

Quality of life [46]: after treatment (2, 6 and 12 months) the patient reported if his/her quality of life was: much better, better, the same, worse or much worse as a consequence of the treatment.

Use of medical services: the numbers and types of LBP-related treatments received in addition to those in the project, and during the whole study period (GP, chiropractor, physiotherapist, hospitalised/surgery or other therapist). Use of pain medication was divided into 5 groups: Nothing/weak pain killers or morphinecontaining medication, both 1-4 or 5-7 days weekly.

\section{Outcomes to assess other treatment aspects}

Number of sessions during the study treatments: treatment costs were estimated by counting the numbers of treatments the patients in the two treatment arms received.

Treatment preference: to assess whether patient treatment preferences had an influence on LBP outcomes, patients were asked, before randomisation, which intervention they would prefer being allocated to.

\section{Data Analysis}

Data from the questionnaires and MRI evaluation forms were entered into a database using Epidata 3.1 (Epidata Association, Odense, Denmark) using double data entry. Errors were corrected by a secretary who was blinded to treatment allocation. Data were transferred to SPSS (SPSS Base 14.0) for statistical analysis.

\section{Statistical analysis}

Demographic variables are presented as summary statistics: medians and inter-quartile ranges (IQR) are used for continuous and ordinal variables. To facilitate inclusion in meta-analyses, outcomes are also reported as mean and SD despite their skewed distribution. Frequencies are reported for binary variables. The primary endpoints were reduction in pain and activity limitation. Treatment groups were compared using an ANCOVA analysis with adjustment for baseline values. As a sensitivity analysis of missing data for the primary and essential secondary outcomes, another ANCOVA analysis was performed, where missing values were imputed with the last observation carried forward. This could be viewed as an intention-totreat analysis. For changes over time within each treatment group, Friedman's Test was used except for work ability, where $\chi^{2}$ was performed. Treatment effect was estimated at each of the three follow-up stages for the primary and secondary outcomes. No interim analyses were planned nor performed in this study.

\section{Role of the funding source}

The sponsors of this study had no role in the scientific process.

\section{Results}

\section{Participant Flow/Study Sample}

The numbers and flow of patients are shown in Fig. 2 . Participants in both groups $(n=105$ and 102) were comparable at baseline, as shown in Table 1 and 2 .

The losses to follow-up were all due to non-attendance, even after a second written invitation. In Denmark, it is considered unethical to pressure participants beyond this.

\section{Outcome measures}

Primary outcome measures

Pain

was significantly reduced over time and approximately equally in the two treatment groups (Table 2).

\section{Activity limitation}

was significantly reduced during the course for EDUC ( $\mathrm{p}<.001$ ) but not for TRAIN ( $\mathrm{p}=.17$ ). A consistent trend $(\mathrm{p}=.09 / .12 / .09$, Table 2$)$ favouring EDUC was seen.

The distribution of the varying levels of changes in pain and activity limitation at one year is depicted in Fig. 3. 


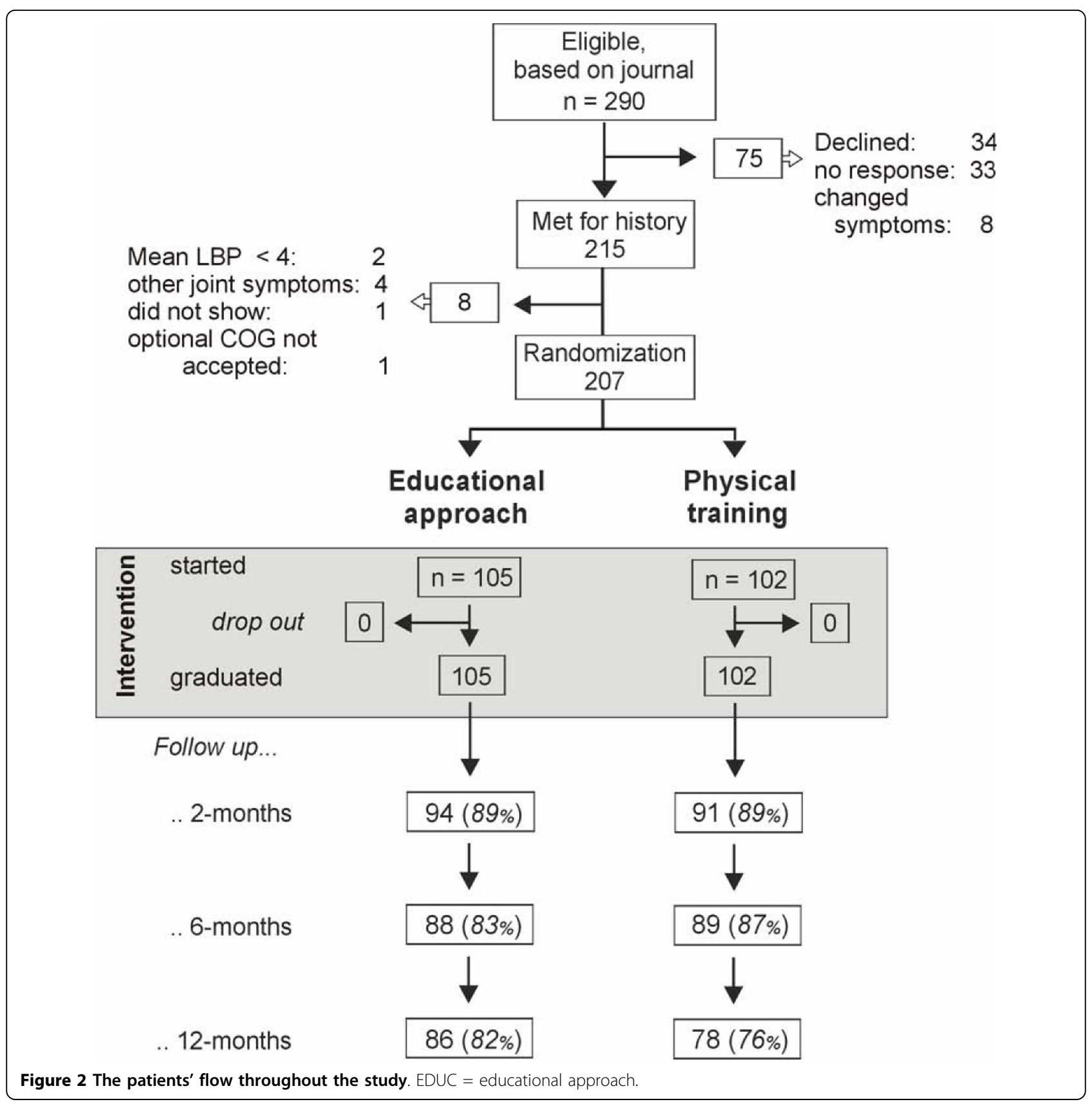

Table 1 Basic characteristics at the time of recruitment beyond the effect variables presented in Table 2

\begin{tabular}{lll}
\hline & Educational approach & Physical Training \\
\hline Age (yrs) & $40(33-48)$ & $38(32-47)$ \\
Sex (women) & $50 \%$ & $55 \%$ \\
BMI & $25(24-29)$ & $25(23-29)$ \\
Work ability & $70 \%$ & $74 \%$ \\
$\begin{array}{l}\text { Rowland-Morris } \\
\text { (scale 0-23) }\end{array}$ & $13(9-16)$ & $13(10-16)$ \\
Smokers (yes) & $35 \%$ & $44 \%$ \\
\hline
\end{tabular}

Data are presented as medians (IQRs) or fractions
A post-hoc analysis $\left(\chi^{2}\right)$ considering clinically relevant improvements $(\geq 5) /$ "no-change" $(4 ;-4)$ /worsening $(\leq-5)$ favoured EDUC significantly at 2 months $(\mathrm{p}=.03$ ), but not significantly at 6 and 12 months). However, a relevant question is whether there was an association between reporting less activity limitation and reduced fear-avoidance belief over time. We therefore made a post-hoc regression analysis on $\Delta$ 'activity limitation' and $\triangle \mathrm{FABQ}$, finding significant associations at all three follow ups $(\mathrm{p}=.04 /<.001 /<.001)$, irrespective of type of treatment $(\mathrm{p}=.16 / .17 / .12)$. 


\section{Secondary outcome measures}

$F A B Q$

showed statistically significant differences between the two groups at all follow-up periods, favouring EDUC. The within-group improvements over time were statistically marginally significant $(\mathrm{p}=.05)$ for EDUC only (Table 2$)$. BBQ was significantly better $(p=.01)$ for
EDUC at 6 months only, but no significant time trend was observed.

Neither reported physical activity and work ability (Table 2) nor quality of life, sick leave and medication showed any significant differences across time or between groups. Data for the latter three are not presented.

Table 2 Outcomes at 2, 6 and 12 months compared with baseline

\begin{tabular}{|c|c|c|c|c|c|c|c|}
\hline & \multicolumn{3}{|c|}{ Educational approach } & \multicolumn{4}{|c|}{ Physical Training } \\
\hline & $\mathbf{n}$ & $\begin{array}{l}\text { Median } \\
\text { (IQR) }\end{array}$ & $\begin{array}{l}\text { Mean } \\
\text { (SD) }\end{array}$ & $\mathbf{n}$ & $\begin{array}{l}\text { Median } \\
\text { (IQR) }\end{array}$ & $\begin{array}{l}\text { Mean } \\
\text { (SD) }\end{array}$ & $p=$ \\
\hline \multicolumn{8}{|l|}{ Primary outcomes } \\
\hline \multicolumn{8}{|l|}{ 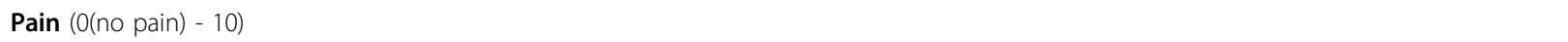 } \\
\hline Baseline & 103 & $6.1(5-7)$ & $6.1(1.4)$ & 99 & $6.5(5-7)$ & $6.3(1.5)$ & \\
\hline 2-mths follow-up & 94 & $4.8(3-6)$ & $4.6(2.1)$ & 91 & $4.7(4-6)$ & $4.9(2.2)$ & .7 \\
\hline 6-mths follow-up & 87 & $4.3(3-6)$ & $4.5(2.3)$ & 89 & $5.0(3-6)$ & $4.8(2.1)$ & .7 \\
\hline 12-mths follow-up & 86 & $4.8(2-6)$ & $4.5(2.4)$ & 78 & $5.1(3-6)$ & $4.8(2.2)$ & .8 \\
\hline Time effect & & $p<.001$ & & & $p<.001$ & & \\
\hline \multicolumn{8}{|c|}{ Activity limitation (Rating Scale) (0(best) -30) } \\
\hline Baseline & 104 & $14(10-17)$ & $14.0(4.7)$ & 98 & $14(11-17)$ & $14.1(4.5)$ & \\
\hline 2-mths follow-up & 94 & $11(6-16)$ & $11.6(6.2)$ & 91 & $13(9-16)$ & $13.0(5.8)$ & .09 \\
\hline 6-mths follow-up & 87 & $11(6-16)$ & $11.2(6.4)$ & 87 & $13(9-17)$ & $12.7(5.4)$ & .12 \\
\hline 12-mths follow-up & 86 & $11(6-16)$ & $11.0(6.8)$ & 78 & $13(9-17)$ & $13.0(5.9)$ & .09 \\
\hline Time effect & & $p<.001$ & & & $p=.17$ & & \\
\hline \multicolumn{8}{|l|}{ Secondary outcomes } \\
\hline \multicolumn{8}{|l|}{ FABQ $(0-24)$} \\
\hline Baseline & 104 & $13(9-18)$ & $13.0(6.1)$ & 102 & $13(9-18)$ & $13.0(6.3)$ & \\
\hline 2-mths follow-up & 86 & $10(6-14)$ & $10.3(5.9)$ & 88 & $14(9-18)$ & $13.3(6.4)$ & $<.001$ \\
\hline 6-mths follow-up & 84 & $11(6-15)$ & $10.8(6.2)$ & 86 & $13(9-18)$ & $13.3(6.0)$ & .007 \\
\hline 12-mths follow-up & 84 & $8.5(6-15)$ & $10.5(6.1)$ & 76 & $13(8-18)$ & $13.1(6.5)$ & .01 \\
\hline Time effect & & $p=.05$ & & & $p=.43$ & & \\
\hline \multicolumn{8}{|l|}{ BBQ (0-54) } \\
\hline Baseline & 105 & $27(18-35)$ & $26.6(10.9)$ & 102 & $28(20-33)$ & $27.1(10.2)$ & \\
\hline 2-mths follow-up & 85 & $23(14-32)$ & $23.1(10.6)$ & 88 & $28(17-36)$ & $25.7(13.0)$ & .17 \\
\hline 6-mths follow-up & 83 & $24(14-33)$ & $24.3(12.7)$ & 86 & $28(22-38)$ & $28.5(11.4)$ & .01 \\
\hline 12-mths follow-up & 86 & $23(14-34)$ & $23.9(12.2)$ & 77 & $28(20-35)$ & $27.2(11.8)$ & .14 \\
\hline Time effect & & $p=.16$ & & & $p=.13$ & & \\
\hline \multicolumn{8}{|c|}{ Misc. phys. activity (min/week) } \\
\hline Baseline & 102 & $330(180-570)$ & $483(525)$ & 102 & $325(199-548)$ & $410(307)$ & \\
\hline 2-mths follow-up & 94 & $415(180-600)$ & $580(1114)$ & 91 & $360(180-720)$ & $561(611)$ & .90 \\
\hline 6-mths follow-up & 85 & $330(220-585)$ & $546(851)$ & 87 & $500(200-700)$ & $545(492)$ & .42 \\
\hline 12-mths follow-up & 86 & $310(180-600)$ & $419(366)$ & 78 & $390(240-611)$ & $480(395)$ & .19 \\
\hline \multirow[t]{2}{*}{ Time effect } & & $p=.67$ & & & $p=.08$ & & \\
\hline & Fraction & & & Fraction & & & \\
\hline \multicolumn{8}{|l|}{ Work ability (Yes/No) } \\
\hline Baseline (\% with Yes) & $73 / 104$ & & & $75 / 102$ & & & \\
\hline 2-mths follow-up & $67 / 93$ & & & $71 / 91$ & & & .35 \\
\hline 6-mths follow-up & $64 / 88$ & & & $68 / 89$ & & & .57 \\
\hline 12-mths follow-up & $63 / 86$ & & & $60 / 78$ & & & .59 \\
\hline Time effect & $p=.97$ & & & $p=.90$ & & & \\
\hline
\end{tabular}

The $p$-values to the right refer to differences in change over time between groups, and the $p$-values below each variable refer to change over time within each treatment group. Medians are presented due to some skewed distributions. 
Sensitivity analysis for the two primary measures, the two LBP-attitude measures (FABQ and BBQ) and 'misc phys. activity' revealed nothing that changed the above conclusions (data not shown).

\section{Health-care contacts outside the project}

There was no statistically significant difference $(\mathrm{p}=$ .65-.87) between the two groups regarding the total number of health-care contacts outside the project (Table 3). The slight difference in mean visits between groups at 2 months was attributed to two EDUC-treated patients having an unusually high number of visits
(79 and 89 over the whole follow-up year) to other health professionals.

\section{Outcomes of other treatment aspects \\ Number of treatments in the project}

EDUC: these patients had 1-6 sessions (median $=3, \mathrm{IQR}$ $=2-3$, mean $=3$ ), each lasting between 30 and 60 minutes. TRAIN: these patients had more sessions (range $=$ $1-20$, median $=6, \mathrm{IQR}=4-10$, mean $=7$ ), each lasting between 30 and 60 minutes. Most treatments were the described training sessions. Forty patients had 1-2 of

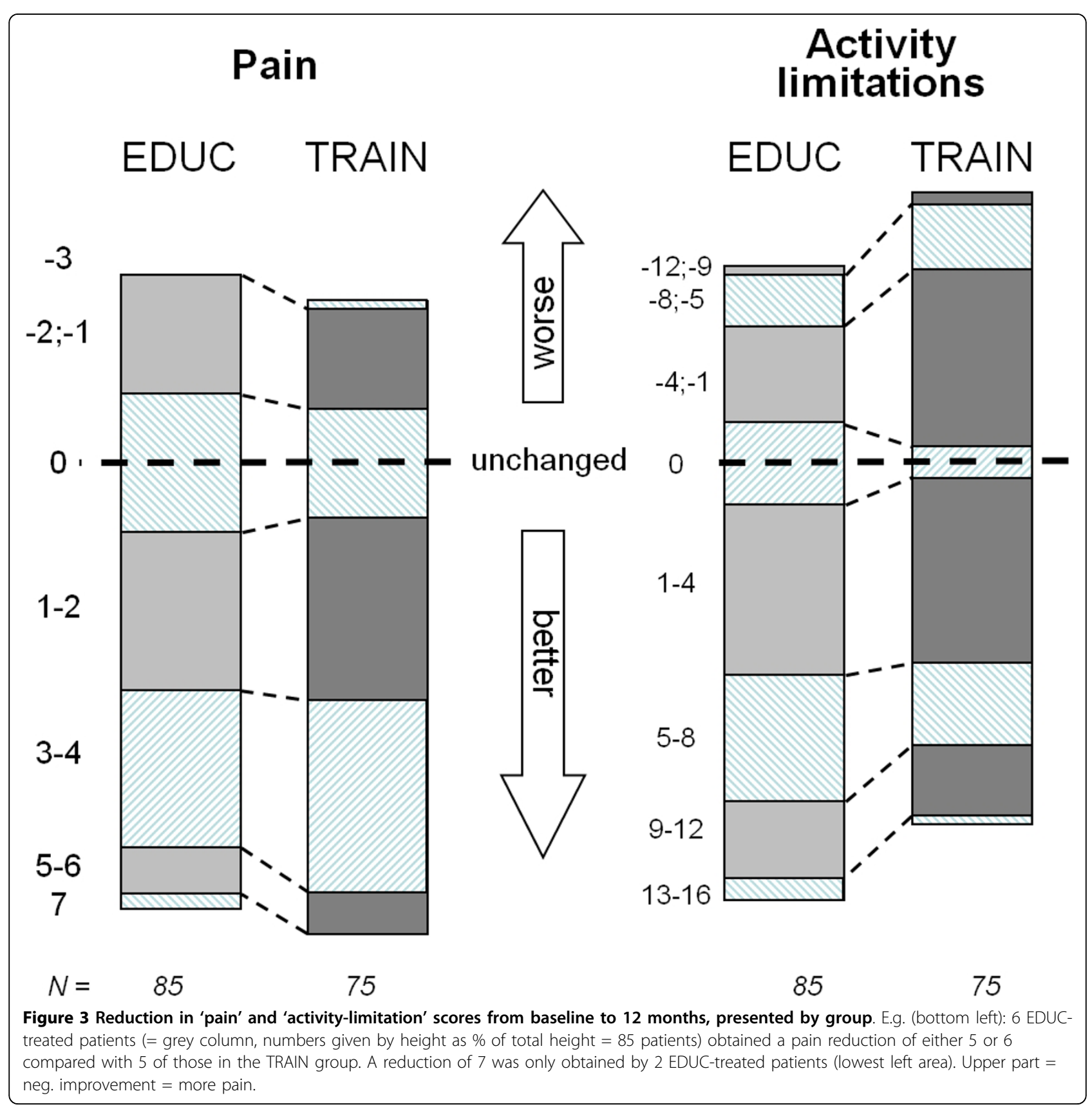


Table 3 Treatments besides those involved in the project

\begin{tabular}{|c|c|c|c|c|c|}
\hline \multirow[b]{2}{*}{$\begin{array}{l}\text { End of treatment } \rightarrow \\
2 \text { months }\end{array}$} & \multicolumn{2}{|c|}{ Educational approach } & \multicolumn{2}{|c|}{ Physical training } & \multirow[b]{2}{*}{$p=$} \\
\hline & $\begin{array}{c}\text { Numbers of visits/ } \\
\text { patients (responders) }\end{array}$ & Mean & $\begin{array}{c}\text { Numbers of visits/ } \\
\text { patients (responders) }\end{array}$ & Mean & \\
\hline$\overline{\mathrm{GP}}$ & $95 / 29$ (93) & 1.0 & $92 / 30(91)$ & 1.0 & \\
\hline Specialist & 15/4 (93) & .2 & 3/1 (91) & .0 & \\
\hline Physiother. & 90/18 (93) & 1.0 & $46 / 11(91)$ & .5 & \\
\hline Chiropractor & $113^{*} / 14(93)$ & 1.2 & $50 / 13(91)$ & .6 & \\
\hline Others & 55/12 (93) & 6 & $21 / 8(91)$ & .2 & \\
\hline Total & 368/41 (93) & 4.0 & 212/45 (91) & 2.3 & .87 \\
\hline \multicolumn{6}{|l|}{$2 \rightarrow 6$ months } \\
\hline GP & $54 / 22(88)$ & 1.6 & $86 / 30(89)$ & 1.9 & \\
\hline Specialist & $5 / 2(88)$ & .3 & 7/3 (89) & .3 & \\
\hline Physiother. & $99 / 13(88)$ & 3.5 & 93/10 (89) & 3.4 & \\
\hline Chiropractor & $61 / 11(88)$ & 2.4 & 49/15 (89) & 1.6 & \\
\hline Others & 74/13 (88) & 2.9 & 65/9 (89) & 2.4 & \\
\hline Total & 276/41 (88) & 3.1 & 271/45 (89) & 3.1 & .65 \\
\hline \multicolumn{6}{|l|}{$6 \rightarrow 12$ months } \\
\hline GP & $95 / 25(86)$ & 1.1 & $140 / 29(77)$ & 1.8 & \\
\hline Specialist & 12/6 (86) & .1 & 17/10 (77) & .2 & \\
\hline Physiother. & 103/18 (86) & 1.2 & $132 / 15(77)$ & 1.7 & \\
\hline Chiropractor & 139/15 (86) & 1.6 & $59 / 10(77)$ & .8 & \\
\hline Others & $90 / 15(86)$ & 1.1 & $51 / 6(77)$ & .7 & \\
\hline Total & 439/45 (86) & 5.1 & $401 / 46(77)$ & 5.2 & .83 \\
\hline
\end{tabular}

The total number of visits are presented as related to those patients making these visits, as well as medians (and IQRs) and means across all those who answered. * One patient had 50 treatments.

their treatments as a part of the multidisciplinary model, visiting a nurse for medication counselling $(n=22)$, seeing a chiropractor $(n=18)$, and/or a doctor $(n=9)$. Moreover, on top of the mentioned number of treatments, 22 of the patients in TRAIN compared with 0 in EDUC were discussed in multi-disciplinary conferences and $36 \%$ of the patients in TRAIN had between 1 and 6 phone consultations compared with $2 \%$ with EDUC.

\section{Type of Physical Training}

initially, 28\% had directional-preference exercises (MDT), $42 \%$ stabilising exercises, $25 \%$ dynamic exercises, and
5\% were unknown. Further treatments: 10 patients: $\mathrm{MDT} \rightarrow$ dynamic; 24 Stability $\rightarrow$ Dynamic; 1 stability $\rightarrow$ MDT; $8 \mathrm{MDT} \rightarrow$ stability.

\section{Patient Preference}

before randomisation, $4 \%$ stated that they would prefer EDUC, and 21\% preferred TRAIN; $73 \%$ had no preference while $2 \%$ didn't respond. The groups were too small for meaningful statistical analyses (Table 4), but at least fulfilling treatment preferences did not lead to better outcomes.

Table 4 Significance of treatment preference before randomisation on LBP and activity limitation

\begin{tabular}{|c|c|c|c|c|c|c|c|c|}
\hline \multirow{3}{*}{$\begin{array}{l}\text { They preferred.. } \\
\text { They got .... } \\
\text { LBP } \\
\text { Baseline }\end{array}$} & \multicolumn{2}{|c|}{$\begin{array}{l}\text {.. educational } \\
\text {.. educational }\end{array}$} & \multicolumn{2}{|c|}{$\begin{array}{l}\text {.. training } \\
\text {.. educational }\end{array}$} & \multicolumn{2}{|c|}{$\begin{array}{l}\text {.. educational } \\
\text {.. training }\end{array}$} & \multicolumn{2}{|c|}{$\begin{array}{l}\text {.. training } \\
\text {.. training }\end{array}$} \\
\hline & \multicolumn{2}{|c|}{$\mathrm{n} /$ median (IQR) } & \multicolumn{2}{|c|}{$\mathrm{n} /$ median (IQR) } & \multicolumn{2}{|c|}{$\mathrm{n} /$ median (IQR) } & \multicolumn{2}{|c|}{$\mathrm{n} /$ median (IQR) } \\
\hline & 4 & $6.5(6-7)$ & 23 & $6(5-7)$ & $4(1)$ & 7.5 (7-9) & 19(1) & $6(5-7)$ \\
\hline 2 months & $3(1)$ & $3(2-6)$ & $22(1)$ & $3(2-6)$ & 5 & $4(3-7)$ & $18(2)$ & $5(2-6)$ \\
\hline $6-$ & $3(1)$ & $5(3-6)$ & $18(5)$ & $4(3-4)$ & 5 & $6(4-7)$ & $18(2)$ & $5(3-6)$ \\
\hline $12-$ & $3(1)$ & $6(3-7)$ & $19(4)$ & $4(1-6)$ & $4(1)$ & $6.5(6-8.5)$ & $16(4)$ & $5(3-5)$ \\
\hline \multicolumn{9}{|l|}{ Activity limitation } \\
\hline Baseline & 4 & $17(15-19)$ & 23 & $13(10-15)$ & 5 & $14(6-19)$ & 20 & $13(11-16)$ \\
\hline 2 months & $3(1)$ & $13(12-16)$ & $22(1)$ & $7.5(6-15)$ & 5 & $13(9-18)$ & $19(1)$ & $12(6-16)$ \\
\hline $6-$ & $3(1)$ & $16(11-16)$ & $18(5)$ & $10(6-12)$ & 5 & $10(8-18)$ & $18(2)$ & $14(7-16)$ \\
\hline $12-$ & $3(1)$ & $16(15-18)$ & $19(4)$ & $10(3-12)$ & $4(1)$ & $12(11-20)$ & $16(4)$ & $11(9-17)$ \\
\hline
\end{tabular}

For those 52 having indicated a treatment preference before randomisation, the numbers in each of the four possible combinations (columns) are presented to the left, with those who did not respond given in brackets where relevant. LBP and activity limitation are given as medians (and IQRs). 


\section{Non-participants}

Patients who initially didn't respond to our written project invitation or refused to participate $(n=81)$ were comparable with those who consented with regard to age, gender, BMI, LBP and activity limitation, but nonparticipants had less sick leave during the previous 12 months.

\section{Non-responders}

Sixteen patients (eight in each group) didn't respond to all three follow-up questionnaires.

Comparisons of the baseline characteristics of nonresponders and responders are shown in Table 5 for the most relevant variables. Of the other baseline characteristics, no obvious differences were seen except for a small trend towards non-responders being generally younger, men and smokers (data not shown).

\section{Miscellaneous}

No side effects were recorded within any treatment group. Numbers needed to treat analysis was not performed due to similar effectiveness of both treatments on most variables.

\section{Discussion}

This is the first study comparing a cognitive educational method based on a non-injury model with that of contemporary symptom-based physical training. We have demonstrated that, among patients with cLBP, the educational/cognitive intervention with few consultations was at least as effective as an individualised, multidisciplinary physical-training approach. 'At least' refers to the observed overall trend of more improvement in activity-limitation with EDUC. There was a statistically significant difference at 2 months in favour of EDUC in the proportion of people improving by a Minimal Important Change (MIC) in activity-limitation (5 or

\begin{tabular}{|c|c|c|c|c|}
\hline & \multicolumn{2}{|c|}{ Educational approach } & \multicolumn{2}{|c|}{ Physical Training } \\
\hline & $\begin{array}{c}\text { non- } \\
\text { responders }\end{array}$ & responders & $\begin{array}{c}\text { non- } \\
\text { responders }\end{array}$ & responders \\
\hline $\mathbf{N}=$ & 8 & 97 & 8 & 94 \\
\hline LBP & $7(5-7)$ & $6(5-7)$ & $6(4-7)$ & $7(5-7)$ \\
\hline Disability & $11(10-15)$ & $13(9.5-17)$ & $14(8,5-18.3)$ & $13(10-16.3)$ \\
\hline FABQ & $9(7-19)$ & $13(9-18)$ & $10(6-18)$ & $13(10-18)$ \\
\hline BBQ & $22(20-38)$ & $27(18-35)$ & $20(14-41)$ & $28(22-33)$ \\
\hline $\begin{array}{l}\text { Phys. } \\
\text { activity }\end{array}$ & $180(120-270)$ & $\begin{array}{c}336(200- \\
600)\end{array}$ & $140(23-449)$ & $\begin{array}{c}330(240- \\
625)\end{array}$ \\
\hline $\begin{array}{l}\text { Work } \\
\text { ability }\end{array}$ & $5 / 8$ & $68 / 97$ & $3 / 8$ & $72 / 9$ \\
\hline
\end{tabular}

Data are presented as medians (IQRs) or fractions. more points on the LBP Rating Scale)[47]. As post-hoc regression analysis showed a relationship between improved activity limitation and improvement in FABQ, and FABQ was more improved in the EDUC group at all three follow-ups, on balance these data appear to favour the EDUC approach.

The cognitive educational approach was based on a non-injury model and had the focus on giving the patients an understanding of the robustness of the spine and the unlikelihood that any normal or even strenuous activity should cause any harm. With this understanding, unconscious neuro-muscular control is believed to encourage natural movements, as opposed to consciously controlled, often tense and awkward movements. Other cognitive interventions for LBP seem more or less to be based on the traditional injury model. By adding even a little caution at the end of such a cognitive session, the patient's likelihood of acquiring better coping strategies may be reduced.

Fear avoidance behaviour may be a natural consequence of the traditional medical model. On the other hand, we have all been reared in the traditional medical model and the chance of giving double messages is likely. In a non-injury model, one is devoid of such caution. Thus, cognitive intervention in a non-injury model poses challenges which are different from interventions based on a traditional model, and comparisons are therefore not useful.

The more marked effect of the cognitive educational approach in the Norwegian studies,[6,8,9] may be explained by a more effective handling of the cognitive components in those studies. An additional explanation is that in the early nineties, the alternative treatment had "be-careful" and "pay-attention-to-the-back" as core elements, which may have increased inappropriate pain-focussing.

Would it be more effective if physical treatment were added to the cognitive intervention? In the authors' opinion, probably not. The basic idea with the present cognitive model is to reduce undue focus on the pain. For many people, a demand for physical training increases pain-focus, especially if they are unable to follow their plan, or if they don't like physical exercise. Given that physical training in cLBP patients generally results in effect sizes of marginal clinical importance, $[48,49]$ it is very likely that any improvement is outweighed by a potential harm to many patients' ability to cope. So far, only a few studies address this issue: Smeets et al.[50] did not find any additional effect of combined cognitive and physical treatment compared with groups where only one of these treatments was employed. On the other hand, Linton et al.[51] found a small additional effect for combined treatment. In Liddle et al.'s review on 'advice to stay active', a combination of exercises was 
recommended, but they did not specifically address the importance of reducing caution and pain-focus[52]. Klabert Moffett et al[53] found, when comparing a combined confidence-directed physical exercise programme added to cognitive components for fear avoiders, that such treatment was superior to general practitioner (GP) management of patients with LBP from 6 weeks to 6 months on the outcome of reduced disability. However, it cannot be concluded from that study if the physical components helped this particular subgroup, because the usually short GP visits are probably not sufficient to change attitude in a fear avoider, as compared with the 1 hour $\times 8$ sessions in the Back-to-Fitness programme[53]. Also, their threshold of 2 as a minimally clinically important difference for the Rowland-Morris Disability Scale should conservatively have been 5[54]. However, it is possible that by adding "the exposure in vivo approach" as proposed by Vlayen would have reinforced our message and might have been particularly effective in such a non-injury model approach [55].

The physical training part of this study was chosen pragmatically on the background of what has become usual practice at a university clinic with physiotherapists who are well trained and well acquainted with evidencebased practice. The trial was not designed to prove efficiency in any subgroups, but to merely reflect current best practice at our clinic and probably also several similar clinics.

Recent studies have further investigated the components used in our study within the symptom-regulated programme[48,56,57]. The efficacy of directional-preference exercises for those who can centralise their pain has gained additional support[58,59]. Stabilising exercises have been further tested by one larger study showing an effect,[60] and three medium-sized studies finding no effect[61-64]. These findings have led to the effectiveness of stabilising exercises being questioned[65-67]. However, some further selection criteria have been elaborated since we started,[68] and therefore it could be that more accurate selection of patients for this treatment might have given different results. Intensive exercise for cLBP has also gained some further evidence[48,57,69]. Although the general effects of training seem to only have marginal clinical effect, $[13,48,57]$ individualised symptom-based strategies such as those used in this study have gained much support during the past few years, showing effectiveness in several studies[36,56,58].

It can be argued that physical training should be supervised for a longer time period than was used in this study, and with higher loads. In support of that argument, Hayden et al. found increased effects in studies with a total of $>20$ hours training, although they also interpreted the effect sizes having marginal clinical impact[48,57].
In the current study, 18 patients in TRAIN had manipulation. Should manipulation have been added systematically? According to Chou et al,[70] it does not seem to add any effect to physical training in cLBP.

However, it might be relevant in initial physical training settings to convince participants that the back can withstand quite heavy-loaded movements, and to identify possible movements that some patients fear, often unconsciously. Bio-feedback/EMG could be used to investigate this[20,71]. In our EDUC setting, only a specific back muscle stretching exercise was practised with the patients. Studies with bio-feedback/EMG to identify such possible fear-related muscle tension might be fruitfully investigated in subsequent studies.

That participants got earlier treatment and that all had an MRI might have also caused a selection bias, but this effect would have been equally distributed in the two groups. MRI was taken to reassure patients that their examination was thorough and to exclude serious pathology.

\section{Conclusion}

A cognitive, educational intervention for cLBP resulted in at least as good outcomes as a symptom-based physical training method despite fewer treatment sessions. The outcome of this study and several corresponding studies and reviews[72-76] indicate that physical training as the core intervention for cLBP should be reconsidered.

\section{List of abbreviations}

ANCOVA: Analysis of co-variances; BBQ: Back believe questionnaire; CLBP: chronic low back pain; EDUC: Educational programme; FABQ: Fear-avoidance beliefs questionnaire; GP: General practitioner; IQR: Interquartile range; LBP: Low back pain; MDT: Mechanical diagnostic therapy; MRI: Magnetic resonance imaging; RMQ: Rowland-Morris disability questionnaire; SD: Standard Deviation; TRAIN: symptom-based physical training programme;

\section{Competing interests}

The authors declare that they have no competing interests.

\section{Authors' contributions}

PHS wrote the protocol and the manuscript together with TB. Performed most practical aspects in running the study, except where blinding prevented her participation. Performed all patient investigations, organised questionnaires, and carried out the statistical analyses, as directed by LK and TB. TB gave ideas to the project. Took an active part in writing the protocol and the manuscript together with PHS and Al. Performed the cognitive treatment with all patients. CM organised the patient flow through the Center. Took part in scientific structuring of the project, and in drafting the manuscript. LK planned and instructed PHS in performing the statistical analyses. Wrote the statistical method section, and adjusted the results chapter to convey the data analyses. DL structured and supervised the symptom-based physical treatment. Al created the specific cognitive method, and trained TB and PHS in the practical aspects of running it with the patients. Took part in the writing process. All have read and approved the final manuscript.

\section{Acknowledgements}

We would like to acknowledge the generous funding granted by: IMK Foundation, Health Insurance Foundation (Sygekassernes Helsefond), Tryg 
Foundationen, Funen County Research Foundation, and Danish Rheumatism Association.

\section{Author details}

${ }^{1}$ The Back Research Center, part of Clinical Locomotion Science, Funen Hospital, Ringe, and the University of Southern Denmark, Denmark. ${ }^{2}$ Actual Address: Research Center for Back Diseases, Glostrup University Hospital, H29, Ndr. Ringvej 57, DK-2600 Glostrup, Denmark. ${ }^{3}$ Department of Statistics, University of Southern Denmark, Odense, Denmark. ${ }^{4}$ Department of Physical Medicine and Rehabilitation, Kysthospitalet Stavern, Norway.

Received: 13 November 2009 Accepted: 17 September 2010 Published: 17 September 2010

\section{References}

1. Crombez G, Vlaeyen JWS, Heuts PHTG, Lysens R: Pain-related fear is more disabling than pain itself: evidence on the role of pain-related fear in chronic back pain disability. Pain 1999, 80:329-339.

2. Linton SJ, Andersson T: Can chronic disability be prevented? A randomized trial of a cognitive-behavior intervention and two forms of information for patients with spinal pain. Spine 2000, 25:2825-2831.

3. Mannion AF, Junge A, Taimela S, Muntener M, Lorenzo K, Dvorak J: Active therapy for chronic low back pain: part 3. Factors influencing self-rated disability and its change following therapy. Spine 2001, 26:920-929.

4. Vlaeyen JW, Linton SJ: Fear-avoidance and its consequences in chronic musculoskeletal pain: a state of the art. Pain 2000, 85:317-332.

5. Al-Obaidi SM, Nelson RM, Al-Awadhi S, Al-Shuwaie N: The role of anticipation and fear of pain in the persistence of avoidance behavior in patients with chronic low back pain. Spine 2000, 25:1126-1131.

6. Indahl A, Haldorsen EH, Holm S, Reikeras O, Ursin H: Five-year follow-up study of a controlled clinical trial using light mobilization and an informative approach to low back pain. Spine 1998, 23:2625-2630.

7. Marhold C, Linton SJ, Melin L: A cognitive-behavioral return-to-work program: effects on pain patients with a history of long-term versus short-term sick leave. Pain 2001, 91:155-163.

8. Hagen EM, Eriksen HR, Ursin H: Does early intervention with a light mobilization program reduce long-term sick leave for low back pain? Spine 2000, 25:1973-1976

9. Indahl A, Velund L, Reikeraas O: Good prognosis for low back pain when left untampered. A randomized clinical trial. Spine 1995, 20:473-477.

10. Sullivan MJ, Stanish WD: Psychologically based occupational rehabilitation: the Pain-Disability Prevention Program. Clin J Pain 2003, 19:97-104.

11. Sullivan MJ, Ward LC, Tripp D, French DJ, Adams H, Stanish WD: Secondary prevention of work disability: community-based psychosocial intervention for musculoskeletal disorders. J Occup Rehabil 2005, 15:377-392.

12. Karjalainen $\mathrm{K}$, Malmivaara A, Pohjolainen $T$, Hurri $H$, Mutanen $P$, Rissanen $P$, et al: Mini-intervention for subacute low back pain: a randomized controlled trial. Spine 2003, 28:533-540.

13. European Guidelines: Cost action B13. Low Back Pain - Guidelines for its management.[http://www.backpaineurope.org], 2004.

14. Magnusson M, Alexiev A, Wilder D, Pope M, Spratt K, Lee SH, et al: Unexpected load and assymetric posture as ethiologic factors in low back pain. European Spine Journal 1996, 5:23-25.

15. Indahl A: Low back pain: diagnosis, treatment, and prognosis. Scand J Rheumatol 2004, 33:199-209.

16. Hodges PW, Moseley GL, Gabrielsson A, Gandevia SC: Experimental muscle pain changes feedforward postural responses of the trunk muscles. Exp Brain Res 2003, 151:262-271.

17. Hodges PW, Moseley GL: Pain and motor control of the lumbopelvic region: effect and possible mechanisms. J Electromyelogr Kinesiol 2003, 13:361-370.

18. Moseley GL, Brhyn L, llowiecki M, Solstad K, Hodges PW: The threat of predictable and unpredictable pain: differential effects on central nervous system processing? Aust J Physiother 2003, 49:263-267.

19. Moseley GL, Nicholas MK, Hodges PW: A randomized controlled trial of intensive neurophysiology education in chronic low back pain. Clin $J$ Pain 2004, 20:324-330.

20. Moseley GL, Nicholas MK, Hodges PW: Does anticipation of back pain predispose to back trouble? Brain 2004, 127:2339-2347.
21. Moseley GL, Hodges PW: Reduced variability of postural strategy prevents normalization of motor changes induced by back pain: a risk factor for chronic trouble? Behav Neurosci 2006, 120:474-476.

22. Moseley GL: A pain neuromatrix approach to patients with chronic pain. Man Ther 2003, 8:130-140.

23. MacDonald D, Moseley GL, Hodges PW: Why do some patients keep hurting their back? Evidence of ongoing back muscle dysfunction during remission from recurrent back pain. Pain 2009, 142:183-188.

24. Battie MC, Videman T, Gibbons LE, Fisher LD, Manninen H, Gill K: 1995 Volvo Award in clinical sciences. Determinants of lumbar disc degeneration. A study relating lifetime exposures and magnetic resonance imaging findings in identical twins. Spine 1995, 20:2601-2612.

25. Videman T, Sarna S, Battie MC, Koskinen S, Gill K, Paananen H, et al: The long-term effects of physical loading and exercise lifestyles on backrelated symptoms, disability, and spinal pathology among men. Spine 1995, 20:699-709.

26. Videman T, Battié MC: The influence of occupation on lumbar degeneration. Spine 1999, 24:1164-1168.

27. Videman T, Simonen R, Usenius J, Osterman K, Battié M: The long-term effects of rally driving on spinal pathology. Clin Biomech (Bristol, Avon) 2000, 15:83-86.

28. Videman T, Battie MC, Ripatti S, Gill K, Manninen H, Kaprio J: Determinants of the progression in lumbar degeneration: a 5-year follow-up study of adult male monozygotic twins. Spine 2006, 31:671-678.

29. Videman T, Gibbons LE, Kaprio J, Battie MC: Challenging the cumulative injury model: positive effects of greater body mass on disc degeneration. Spine J 2010, 10:26-31.

30. Kjaer M, Langberg H, Miller BF, Boushel R, Crameri R, Koskinen S, et al: Metabolic activity and collagen turnover in human tendon in response to physical activity. J Musculoskelet Neuronal Interact 2005, 5:41-52.

31. Wall ME, Banes AJ: Early responses to mechanical load in tendon: role for calcium signaling, gap junctions and intercellular communication. $J$ Musculoskelet Neuronal Interact 2005, 5:70-84.

32. Hansson $\mathrm{TH}$, Hansson EK: The effects of common medical interventions on pain, back function, and work resumption in patients with chronic low back pain: A prospective 2-year cohort study in six countries. Spine 2000, 25:3055-3064.

33. Waddell G, Burton AK: Occupational health guidelines for the management of low back pain at work: evidence review. Occup Med (Lond) 2001, 51:124-135.

34. Hartvigsen J, Bakketeig LS, Leboeuf-Yde C, Engberg M, Lauritzen T: The association between physical workload and low back pain clouded by the "healthy worker" effect: population-based cross-sectional and 5-year prospective questionnaire study. Spine 2001, 26:1788-1793.

35. Hoogendoorn WE, van Poppel MN, Bongers PM, Koes BW, Bouter LM: Physical load during work and leisure time as risk factors for back pain. Scand J Work Environ Health 1999, 25:387-403.

36. Fritz JM, Delitto A, Erhard RE: Comparison of classification-based physical therapy with therapy based on clinical practice guidelines for patients with acute low back pain: a randomized clinical trial. Spine 2003, 28:1363-1371.

37. Albert $\mathrm{H}$, Manniche $\mathrm{C}$ : The efficacy of active conservative treatment for patients with severe sciatica. A single-blind randomized clinical controlled trial. Spine.

38. Long A, Donelson R, Fung T: Does it Matter Which Exercise?: A Randomized Control Trial of Exercise for Low Back Pain. Spine 2004, 29:2593-2602.

39. Goldby LJ, Moore AP, Doust J, Trew ME: A randomized controlled trial investigating the efficiency of musculoskeletal physiotherapy on chronic low back disorder. Spine 2006, 31:1083-1093.

40. Hides JA, Jull GA, Richardson CA: Long-term effects of specific stabilizing exercises for first-episode low back pain. Spine 2001, 26:E243-E248.

41. Rasmussen-Barr E, Nilsson-Wikmar L, Arvidsson I: Stabilizing training compared with manual treatment in sub-acute and chronic low-back pain. Man Ther 2003, 8:233-241.

42. Manniche C, Asmussen $K$, Lauritsen B, Vinterberg $H$, Kreiner $S$, Jordan A: Low back pain rating scale: validation of a tool for assessment of low back pain. Pain 1994, 57:317-326

43. Roland M, Morris R: A study of the natural history of back pain. Part I: development of a reliable and sensitive measure of disability in lowback pain. Spine 1983, 8:141-144. 
44. Waddell G, Newton M, Henderson I, Somerville D, Main CJ: A FearAvoidance Beliefs Questionnaire (FABQ) and the role of fear-avoidance beliefs in chronic low back pain and disability. Pain 1993, 52:157-168.

45. Symonds TL, Burton AK, Tillotson KM, Main CJ: Do attitudes and beliefs influence work loss due to low back trouble? Occup Med 1996, 46:25-32.

46. Bendix AF, Bendix $T$, Labriola $M$, Bækgaard $P$ : Functional restoration for chronic low back pain. Two-year follow up of two randomized, clinical trials. Spine 1998, 23:717-725

47. Lauridsen HH, Hartvigsen J, Manniche C, Korsholm L, Grunnet-Nilsson N: Responsiveness and minimal clinically important difference for pain and disability instruments in low back pain patients. BMC Musculoskelet Disord 2006, 7:82.

48. Hayden JA, van Tulder MW, Malmivaara AV, Koes BW: Meta-analysis: exercise therapy for nonspecific low back pain. Ann Intern Med 2005, 142:765-775.

49. Jordan K, Dunn KM, Lewis M, Croft P: A minimal clinically important difference was derived for the Roland-Morris Disability Questionnaire for low back pain. J Clin Epidemiol 2006, 59:45-52.

50. Smeets RJ, Vlaeyen JW, Hidding A, Kester AD, van der Heijden GJ, van Geel AC, et al: Active rehabilitation for chronic low back pain: cognitivebehavioral, physical, or both? First direct post-treatment results from a randomized controlled trial [ISRCTN22714229]. BMC Musculoskelet Disord 2006, 7:5.

51. Linton SJ, Boersma K, Jansson M, Svard L, Botvalde M: The effects of cognitive-behavioral and physical therapy preventive interventions on pain-related sick leave: a randomized controlled trial. Clin J Pain 2005, 21:109-119.

52. Liddle SD, Gracey JH, Baxter GD: Advice for the management of low back pain: a systematic review of randomised controlled trials. Man Ther 2007, 12:310-327.

53. Klaber Moffett JA, Carr J, Howarth E: High fear-avoiders of physical activity benefit from an exercise program for patients with back pain. Spine 2004, 29:1167-1172

54. Ostelo RW, Deyo RA, Stratford P, Waddell G, Croft P, Von KM, et al: Interpreting change scores for pain and functional status in low back pain: towards international consensus regarding minimal important change. Spine 2008, 33:90-94.

55. Leeuw M, Goossens ME, van Breukelen GJ, de Jong JR, Heuts PH, Smeets RJ, et al: Exposure in vivo versus operant graded activity in chronic low back pain patients: results of a randomized controlled trial. Pain 2008, 138:192-207.

56. Brennan GP, Fritz JM, Hunter SJ, Thackeray A, Delitto A, Erhard RE: Identifying subgroups of patients with acute/subacute "nonspecific" low back pain: results of a randomized clinical trial. Spine 2006, 31:623-631.

57. Hayden JA, van Tulder MW, Tomlinson G: Systematic review: strategies for using exercise therapy to improve outcomes in chronic low back pain. Ann Intern Med 2005, 142:776-785.

58. Browder DA, Childs JD, Cleland JA, Fritz JM: Effectiveness of an extensionoriented treatment approach in a subgroup of subjects with low back pain: a randomized clinical trial. Phys Ther 2007, 87:1608-1618.

59. Machado LA, de Souza MS, Ferreira PH, Ferreira ML: The McKenzie method for low back pain: a systematic review of the literature with a metaanalysis approach. Spine 2006, 31:E254-E262.

60. Ferreira ML, Ferreira PH, Latimer J, Herbert RD, Hodges PW, Jennings MD, et al: Comparison of general exercise, motor control exercise and spinal manipulative therapy for chronic low back pain: A randomized trial. Pain 2007, 131:31-37.

61. Cairns MC, Foster NE, Wright C: Randomized controlled trial of specific spinal stabilization exercises and conventional physiotherapy for recurrent low back pain. Spine 2006, 31:E670-E681.

62. Koumantakis GA, Watson PJ, Oldham JA: Supplementation of general endurance exercise with stabilisation training versus general exercise only. Physiological and functional outcomes of a randomised controlled trial of patients with recurrent low back pain. Clin Biomech 2005, 20:474-482.

63. Koumantakis GA, Watson PJ, Oldham JA: Trunk muscle stabilization training plus general exercise versus general exercise only: randomized controlled trial of patients with recurrent low back pain. Phys Ther 2005, 85:209-225.
64. Critchley DJ, Ratcliffe J, Noonan S, Jones RH, Hurley MV: Effectiveness and cost-effectiveness of three types of physiotherapy used to reduce chronic low back pain disability: a pragmatic randomized trial with economic evaluation. Spine 2007, 32:1474-1481.

65. May S, Johnson R: Stabilisation exercises for low back pain: a systematic review. Physiotherpy 2008, 94:179-189.

66. Standaert CJ, Weinstein SM, Rumpeltes J: Evidence-informed management of chronic low back pain with lumbar stabilization exercises. Spine J 2008, 8:114-120.

67. Lederman E: The Myth of Core Stability. Journal of Bodywork and Movement Therapies 2009.

68. Hicks GE, Fritz JM, Delitto A, McGill SM: Preliminary development of a clinical prediction rule for determining which patients with low back pain will respond to a stabilization exercise program. Arch Phys Med Rehabil 2005, 86:1753-1762.

69. Mayer J, Mooney V, Dagenais S: Evidence-informed management of chronic low back pain with lumbar extensor strengthening exercises. Spine J 2008, 8:96-113.

70. Chou R, Huffman LH: Medications for acute and chronic low back pain: a review of the evidence for an American Pain Society/American College of Physicians clinical practice guideline. Ann Intern Med 2007, 147:505-514.

71. van der Hulst M, Vollenbroek-Hutten MM, Rietman JS, Schaake L, GroothuisOudshoorn KG, Hermens HJ: Back muscle activation patterns in chronic low back pain during walking: a "guarding" hypothesis. Clin J Pain 2010 26:30-37.

72. Vlaeyen JW, Morley S: Cognitive-behavioral treatments for chronic pain: what works for whom? Clin J Pain 2005, 21:1-8.

73. Gatchel RJ, Rollings KH: Evidence-informed management of chronic low back pain with cognitive behavioral therapy. Spine J 2008, 8:40-44.

74. Brox Jl, Storheim K, Grotle M, Tveito TH, Indahl A, Eriksen HR: Systematic review of back schools, brief education, and fear-avoidance training for chronic low back pain. Spine J 2008, 8:948-958.

75. Kovacs FM, Abraira V, Royuela A, Corcoll J, Alegre L, Cano A, et al: Minimal clinically important change for pain intensity and disability in patients with nonspecific low back pain. Spine 2007, 32:2915-2920.

76. Engers $A$, Jallema $P$, Wensing $M$, van der Windt DA, Grol $R$, van Tulder MW: Individual patient education for low back pain (review). The Cochrane Library 2008, 1.

\section{Pre-publication history}

The pre-publication history for this paper can be accessed here: http://www.biomedcentral.com/1471-2474/11/212/prepub

doi:10.1186/1471-2474-11-212

Cite this article as: Sorensen et al:: An educational approach based on a non-injury model compared with individual symptom-based physical training in chronic LBP. A pragmatic, randomised trial with a one-year follow-up. BMC Musculoskeletal Disorders 2010 11:212.

\section{Submit your next manuscript to BioMed Central and take full advantage of:}

- Convenient online submission

- Thorough peer review

- No space constraints or color figure charges

- Immediate publication on acceptance

- Inclusion in PubMed, CAS, Scopus and Google Scholar

- Research which is freely available for redistribution

Submit your manuscript at www.biomedcentral.com/submit
Biomed Central 